\title{
Frailty and Post-Operative Outcomes in the Older Patients Undergoing Elective Posterior Thoracolumbar Fusion Surgery
}

This article was published in the following Dove Press journal: Clinical Interventions in Aging

\section{Wenzhi Sun (D) \\ Shibao Lu \\ Chao Kong \\ Zhongen Li \\ Peng Wang \\ Sitao Zhang}

Department of Orthopaedics, Capital Medical University Xuanwu Hospital, Beijing 100053, People's Republic of China
Correspondence: Shibao Lu Email xuanwuspine@sina.com
Background and Aim: Frailty is an independent predictor of mortality and adverse events (AEs) in patients undergoing surgery. This study aimed to quantify the ability of Modified Frailty Index $(\mathrm{mFI})$ to predict AEs in older patients undergoing elective posterior thoracolumbar fusion surgery.

Methods: We retrospectively reviewed the results of 426 patients with the following diagnoses and follow-up evaluations of at least 12 months duration: lumbar disc herniation, 125; degenerative spondylolisthesis, 81; lumbar spinal canal stenosis, 187; and adult spinal deformities, 33. The cases were divided into two groups. The long spinal fusion (LSF) group was defined as $\geq 3$ spinal levels with segmental pedicle-screw fixation. Short spinal fusion (SSF) were defined with at most two levels. The mFI used in the present study is an 11variable assessment. The association of frailty with AEs was determined after adjusting for known and suspected confounders.

Results: Frailty was presented in 66 patients $(15.5 \%)$ within the total population (LSF, $21.9 \%$ and SSF, $11.8 \%$ ). Rates of AEs assessed in the study increased stepwise with an increase in the $\mathrm{mFI}$ for the two groups. The severity of frailty was an independent predictor of any, major, and minor complications in the LSF group and any, minor complication in the $\mathrm{SSF}$ group $(\mathrm{P}<0.05)$. A comparison of post-operative clinical outcomes showed that the ODI and SF-36 scores deteriorated as the mFI increased.

Conclusion: Frailty was shown to be an independent predictor of AEs in older patients undergoing elective posterior thoracolumbar fusion surgery, especially for patients undergoing LSF.

Keywords: frailty, degenerative spine disease, spinal surgery, elderly, clinical evaluation, complications, risk stratification

\section{Introduction}

In China, the world's most populous nation, the proportion of the population $\geq 65$ years of age is projected to triple from $9.6 \%$ in 2015 to $27.6 \%$ in 2050 , and the oldage dependency ratio is anticipated to increase from 0.13 to 0.47 during the same period. ${ }^{1}$ An increasing number of older patients will undergo surgical treatment for degenerative spine disease (DSD), which is likely because of the advancements in surgical technique, improved anesthesia, patient expectations, and increasing longevity. Despite the advances in surgical and anesthetic techniques, peri-operative complications, and mortality in geriatric patients are relatively higher, which impact costs, bad outcomes, and long-term survival. ${ }^{2-4}$ Thus, preventing mortality and outcomes after surgical procedures is imperative for surgeons. 
A previously reported tool, the American Society of Anesthesiologists (ASA) Physical Status Classification System, is a useful measure of co-morbidity to predict complications in a younger adult cohort. ${ }^{5-7}$ Nevertheless, the ASA patient classification is quite subjective and a significant level of disagreement exists, even between qualified specialists. ${ }^{8}$ The ASA patient classification is limited in its capability to precisely stratify patient risk with mild co-morbidities. ${ }^{9,10}$ The validity of the ASA system, its usefulness, and the need for a new, more precise scoring system is discussed.

In recent years there has been an increased use of the concept of frailty as a predictor of patients' operative risk. Frailty represents a state of weakened reserve against even minor stressors and may not correlate with chronologic age. ${ }^{11,12}$ The Canadian Study of Health and Aging Frailty Index (CSHA-FI) is a comprehensive, 70-item list that assesses deficits with respect to physical, cognitive, functional, and social domains to determine frailty. ${ }^{13}$ This list has been simplified into the Modified Frailty Index (mFI), which is based on 11 co-morbidities and functional status obtained from the patient's chart to stratify risk and predict adverse events in multiple surgical specialties. ${ }^{9,10,14-24}$

Frailty has long been recognized as a clinical syndrome that may serve as a tool to predict mortality and adverse events (AEs). Indeed, the effect of frailty on elective thoracolumbar surgery outcomes is still under discussion. In contrast to other surgical groups, the mFI did not predict acute care complications in a select population of older patients undergoing simple lumbar surgery for DSD. ${ }^{25}$ Therefore, invasive surgery may be a confounding factor for the $\mathrm{mFI}$ on outcomes of surgeries. Moreover, Yagi et $\mathrm{al}^{26}$ demonstrated that treatment for frailty did not improve the risk of complications in surgery for DSD. Therefore, it is imperative to confirm the utility of the $\mathrm{mFI}$ in predicting AEs and mortality after surgery for DSD. The present study was conducted to investigate the relationships between $\mathrm{mFI}$ and mortality and AEs in long and short spinal fusion groups.

\section{Patients and Methods}

\section{Patient Population}

We retrospectively reviewed data for consecutive subjects with DSD who underwent elective posterior thoracolumbar fusion surgery (T9-S1) between 1 January 2016 and 31 August 2018 and completed 12 months of follow-up evaluations. The cases were divided into two groups. The long spinal fusion (LSF) group was defined as greater than two fused spinal levels with segmental pedicle-screw fixation from the upper to lower instrumented vertebrae. Patients undergoing short spinal fusion (SSF) were defined with at most two levels. We evaluated 426 subjects with the following diagnoses: lumbar disc herniation (LDH), 125; degenerative spondylolisthesis (DS), 81; lumbar spinal canal stenosis (LSCS), 187; and adult spinal deformities (ASD), 33. All patients were enrolled prospectively and analyzed retrospectively. The present study was approved by our Institution Review Board.

\section{Inclusion and Exclusion Criteria}

We included patients $>65$ years of age because frailty is more prevalent in this age group. We included patients with DSD, including LDH, DS, LSCS, and ASD. The exclusion criteria included missing pre-operative data, emergencies, open wounds, current sepsis, pneumonia, cardiopulmonary resuscitation before surgery, prior surgery within 30 days, non-elective trauma, or neoplasm of the spine. We also excluded patients with significant deformities that required an osteotomy, revision surgery, and a previous anterior approach to the spine.

\section{Data Collection and Clinical Evaluation}

We collected the following demographic data for each patient: age; gender; body mass index (BMI); and comorbidities. The $\mathrm{mFI}$ and ASA were determined from baseline demographics. We also recorded the following surgical data: pre-operative diagnosis; number of posterior fused vertebrae; complications; and surgical history. The Short Form (SF)-36 and Oswestry Disability Index (ODI) were completed for all subjects at baseline and 12 months after surgery.

\section{Modified Frailty Index}

The mFI we used in the study is an 11-variable assessment described by Saxton and Velanovich, ${ }^{27}$ mapping 16 (National Surgical Quality Improvement Program, NSQIP) variables to 11 variables in the CHSA-FI. A prior study has validated the determination of frailty using as few as 10 variables. ${ }^{28}$ An mFI score was calculated for each subject by dividing the number of variables by the total number of deficits present $(\mathrm{n} / 11)$, thus providing an index with a range of $0-1$. The 11 variables were diabetes mellitus, functional status (independent or not independent), chronic obstructive pulmonary disease or pneumonia, congestive heart failure, myocardial infarction, percutaneous coronary intervention and/or stenting or angina, hypertension requiring 
medication, peripheral vascular disease or ischemic rest pain, impaired sensorium, transient ischemic attack or cerebrovascular accident (CVA), and CVA with deficits.

We categorized patients as not frail $(\mathrm{mFI}=0)$, pre-frail $(\mathrm{mFI}<0.21)$, or frail $(\mathrm{mFI} \geq 0.21)$ based on previous data defining frailty as an index $>0.21 .^{29}$

\section{Post-Operative AEs}

Our primary outcomes of interest included any complication, major and minor complications, and mortality. Any complication was defined as intra-operative complications (eg, dural tear, instrumentation failure, and positioningrelated complications), post-operative complications (eg, pneumonia, sepsis, deep vein thrombosis, pulmonary embolism, surgical site infections, central nervous system complication, sepsis/septic shock, cardiac arrest, acute renal failure, and urinary tract infections), 30-day re-operation, and re-admission or mortality that occurred within 12 months from surgery. Major complications were defined as conditions that were life threatening or that could adversely affect the treatment outcome. Complications noted in the medical records but that did not compromise outcomes were considered minor complications. ${ }^{30}$

Secondary outcomes included adverse discharge and length of stay (LOS). Adverse discharge was defined as discharge of a patient to a facility other than home, such as a skilled nursing or rehabilitation facility.

This study retrospectively extracted the patient's data without any intervention measures and we guaranteed the confidentiality of patient's data. Hence patient consent was waived. The procedure performed in the study involving human participants was in accordance with the ethical standards of the Institutional and/or National Research Committee at which the study was conducted (the Ethics Committee of Beijing Xuanwu Hospital of Capital Medical University) and with the 1964 Helsinki Declaration and its later amendments or comparable ethical standards.

\section{Statistical Analysis}

Data are described as means and standard deviations for continuous variables, and the frequencies and percentages for categorical variables. Changes between baseline and post-operative values were analyzed by a paired $t$-test. Multivariate logistic regression analyses were performed to further determine the independent association of frailty index with post-operative AEs, adjusting for possible confounding variables. Odds ratios were calculated with $95 \%$ confidence intervals. A p value $<0.05$ was considered statistically significant. All statistical analyses were performed using SPSS software (version 24; IBM, Armonk, NY, USA).

\section{Results}

Overall, there were 155 LSF and 271 SSF patients who met the inclusion and exclusion criteria for the current study. For the LSF group, the average age was 73.3 years and $73.5 \%$ were female, whereas the average age was 72.4 years and $62.4 \%$ were female among those in the SSF group. Greater than $35.5 \%$ of LSF patients were assigned ASA class $\geq 2$, whereas only $25.5 \%$ of SSF patients were ASA class $\geq 2$. The patient characteristics are outlined in Table 1.

\section{Frailty Index Distribution}

Frailty was present in 66 patients $(15.5 \%)$ within the total population $(21.9 \%$ of the LSF group and $11.8 \%$ of the SSF group). Patients who underwent LSF had a mean (SD, range) mFI of $0.15(0.09,0-0.36)$ and those who underwent SSF had a mean (SD, range) mFI of $0.13(0.19$, $0-0.36)$. The distributions of $\mathrm{mFI}$ scores for both groups are provided in Figure 1A and B.

Table I Demographics of Patients with Degenerative Spine Disease Undergoing LSF and SSF

\begin{tabular}{|l|l|l|}
\hline & LSF & SSF \\
\hline N & 155 & 27 I \\
Average age, yrs & 73.3 & 72.4 \\
\hline Gender, \% & & \\
Female & 73.5 & 62.4 \\
Male & 26.5 & 37.6 \\
\hline BMI, \% & & \\
Nonobese (BMI I8.5-29.9) & 76.8 & 86.7 \\
<I8.5 & 7.7 & 1.8 \\
Obese (BMI $\geq 30)$ & 15.5 & 11.5 \\
\hline ASA class, \% & & \\
I-No disturb & 11.6 & 23.6 \\
2-Mild disturb & 52.9 & 50.9 \\
3-Severe disturb & 32.9 & 24.0 \\
4-Life threat & 2.6 & 1.5 \\
5-Moribund & 0.0 & 0.0 \\
\hline Surgical level & 4.1 & 1.7 \\
\hline
\end{tabular}

Abbreviations: LSF, long spinal fusion; ASA, American Society of Anesthesiologists; BMI, body mass index; SSF, short spinal fusion. 

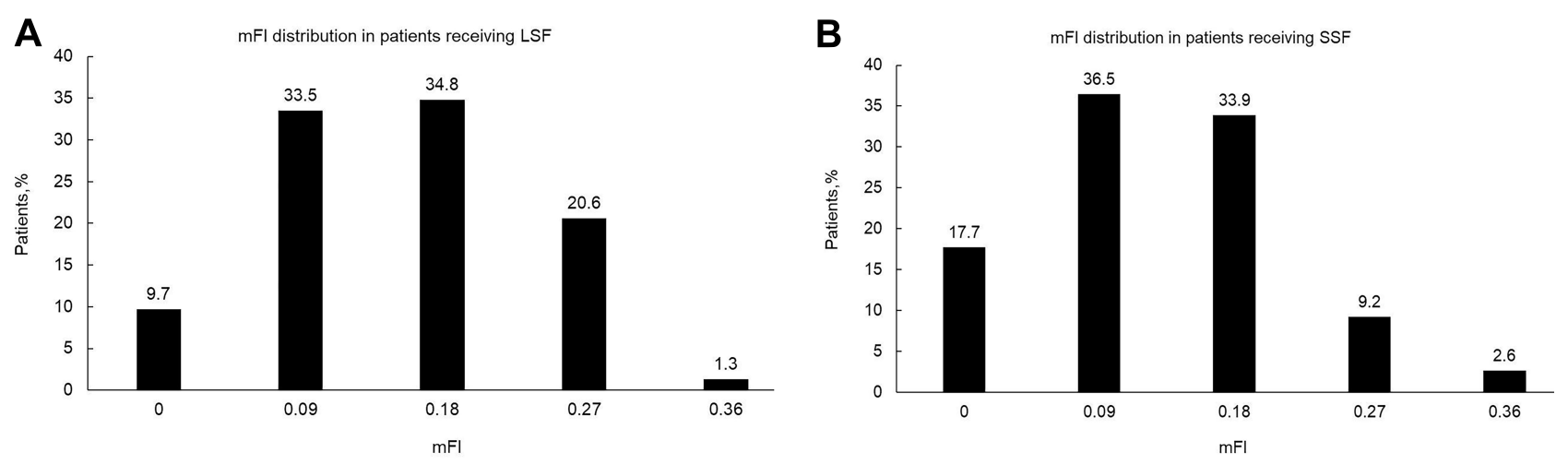

Figure I $(\mathbf{A}) \mathrm{mFI}$ distribution in patients undergoing long spinal fusion. Mean $(\mathrm{SD})=0.15(0.09)$. (B) $\mathrm{mFI}$ distribution in patients undergoing short spinal fusion. Mean $(\mathrm{SD})=$ 0.13 (0.19). LSF, long spinal fusion; SSF, short spinal fusion.

\section{MFI as a Predictor of Post-Operative AEs}

Rates of post-operative AEs assessed in the current study increased stepwise with an increase in the mFI for the LSF and SSF groups. As the $\mathrm{mFI}$ increased from 0 to 0.36 , any complication, major complications, minor complications, and adverse discharge rates increased from $6.7 \%$ to $100 \%$, $6.7 \%$ to $100 \%, 6.7 \%$ to $50 \%$, and $6.7 \%$ to $50 \%$ for the LSF cohort, respectively. The same trend toward complications was also observed in the SSF group, as shown in Figure $2 \mathrm{~A}$ and $\mathrm{B}$. The LOS increased from 16.9 days ( \pm 5.5 days) to 29.0 days ( \pm 14.1 days) in the LSF group and from 13.4 days ( \pm 3.4 days) to 19.7 days ( \pm 3.8 days) in the SSF group for $\mathrm{mFI}$ scores between 0 and 0.36 (Figure 3 ).

\section{Multivariate Logistic Regression Analysis}

Multivariable logistic regression models were used to compare the relative strength of association between $\mathrm{mFI}$ with AEs, such as any complications, major complications, minor complications, and adverse discharge (Table 2). For the LSF group, the only risk factor for any complications and adverse discharge was $\mathrm{mFI}(\mathrm{OR}=12.384, \mathrm{CI}=4.284-35.798, \mathrm{P}<0.001$; and $\mathrm{OR}=3.442, \mathrm{CI}=1.119-10.588, \mathrm{P}=0.031$, respectively). The risk factors for perioperative major complications were BMI $(\mathrm{OR}=2.624, \mathrm{CI}=1.464-4.705, \mathrm{P}=0.001)$ and $\mathrm{mFI}(\mathrm{OR}=5.680$, $\mathrm{CI}=2.078-15.525, \mathrm{P}=0.001)$. The risk factors for perioperative minor complications were age $(\mathrm{OR}=0.889, \mathrm{CI}=0.810-0.974$, $\mathrm{P}=0.012)$ and $\mathrm{mFI}(\mathrm{OR}=6.430, \mathrm{CI}=2.133-19.389, \mathrm{P}=0.001)$. Based on multivariable regression analysis, the only risk factor for any complications was $\mathrm{mFI}(\mathrm{OR}=3.901, \mathrm{CI}=1.792-8.489$, $\mathrm{P}=0.001)$ in $\mathrm{SSF}$. Age $(\mathrm{OR}=1.067, \mathrm{CI}=1.003-1.135, \mathrm{P}=0.041)$ and $\mathrm{mFI}(\mathrm{OR}=2.381, \mathrm{CI}=1.066-5.319, \mathrm{P}=0.034)$ were also risk factors of minor complications in SSF. The only risk factor for adverse discharge was ASA $(\mathrm{OR}=3.643, \mathrm{CI}=1.240-10.702$, $\mathrm{P}=0.019)$. No risk factors for major complications were identified in SSF.

\section{Clinical Outcomes According to $\mathrm{mFI}$ Severity}

Comparisons of post-operative clinical outcomes showed that both the ODI and SF-36 scores deteriorated in the LSF
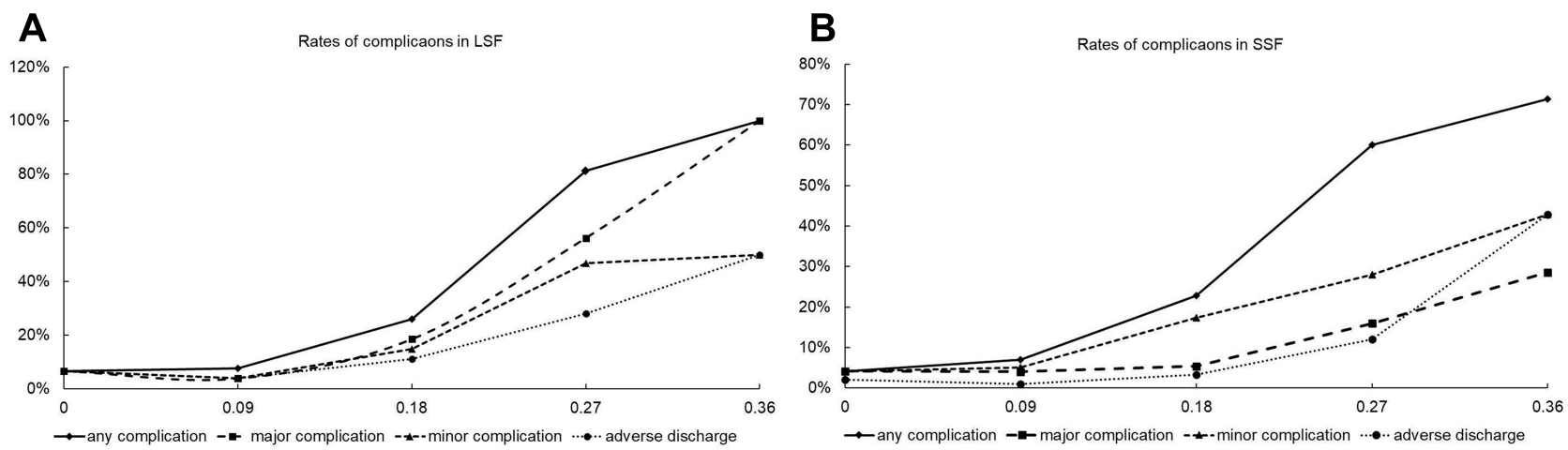

Figure 2 Percentage of post-operative adverse outcomes following elective posterior thoracolumbar fusion surgery. (A) The rates of complications in the LSF group increased as the $\mathrm{mFI}$ increased. (B) The rates of complications increased as the $\mathrm{mFI}$ increased in the SSF cohort. 


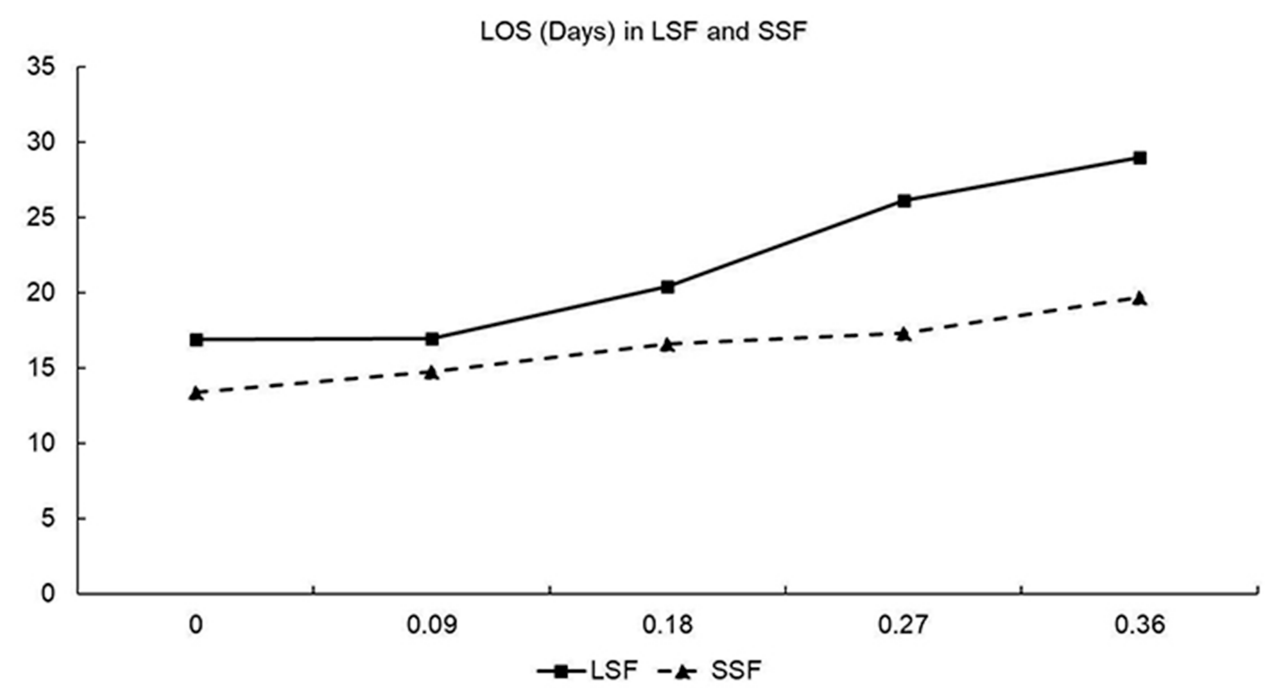

Figure 3 The length of stay after elective posterior thoracolumbar fusion surgery increased as the mFI score increased.

and SSF groups with an increase in the mFI (LSF not frail: ODI $0.152 \pm 0.115$, SF-36 0.821 \pm 0.107 ; LSF prefrail: ODI $0.175 \pm 0.114$, SF-36 $0.728 \pm 0.135$; LSF frail: ODI 0.221 \pm 0.107, SF-36 $0.593 \pm 0.121$; SSF not frail: ODI 0.120 \pm 0.094 , SF-36 $0.817 \pm 0.119$; SSF prefrail: ODI 0.147 \pm 0.096 , SF-36 0.763 \pm 0.126 ; SSF frail: ODI $0.156 \pm 0.103$, SF-36 0.608 \pm 0.154$)$. Both the ODI and SF-36 scores improved after surgery compared with the pre-operative scores regardless of $\mathrm{mFI}$ severity in the two groups, as shown in Figure 4A-D.

\section{Discussion}

Evidence-based risk assessment tools play an important role in pre-operative patient counseling, complementing clinical insight to provide both patients and physicians with a more accurate prediction of outcomes following surgery. Frailty has been previously recognized as an independent risk factor for post-operative AEs in older patients undergoing surgical intervention. ${ }^{12}$

Despite the identification of frailty as a significant predictor of AEs, there is no consensus on the definition of frailty or how to best assess and diagnose frailty. Two major models of defining frailty are the frailty phenotype and the deficit accumulation model, also known as the frailty index. The frailty phenotype is a model that defines frailty based on five phenotypes (unintentional weight loss, grip strength, fatigue, gait speed, and low activity level). ${ }^{31}$ Although clinically reproducible, the frailty phenotype lacks the more easily conceptual mathematical properties with the associated ability to make clinical inferences based on numerical calculations. The deficit accumulation model counts the number of deficits in health across multiple organ systems to obtain a single score that is representative of the overall frailty level of patients. Nevertheless, multiple frailty indices exist. The leading frailty indices in the spine literature are as follows: $\mathrm{mFI}$; Adult Spinal Deformity Frailty Index (ASD-FI); and the Cervical Deformity Frailty Index (CD-FI). ${ }^{32-35}$ Although both the frailty index model and frailty phenotype measures have pros and cons, some have concluded that the frailty index model remains the most versatile with wide applicability for both research and clinical use, as it quantifies the concept of frailty. ${ }^{36,37}$ Moskven et $\mathrm{al}^{38}$ identified $\mathrm{mFI}$ as the most viable current option for assessing, quantifying, and stratifying the severity of frailty in patients undergoing spine surgery. In the current study we elected to use an $\mathrm{mFI}$ based on the CSHA-FI. It has been reported that when using the CSHA-FI a combination of any ten items from the index result in a similar predictive value for the calculated frailty score. ${ }^{39}$ Pairing the original 70-item CSHA-FI to an 11-item $\mathrm{mFI}$ is more practical and requires less time to obtain the data and perform the analysis. The 11-item mFI has also been widely used in non-spinal surgeries, such as head and neck surgery, ${ }^{15}$ elective abdominal aortic aneurysm repair, ${ }^{16}$ lobectomy, ${ }^{17}$ curative surgery for urologic malignancy, ${ }^{18}$ primary total hip arthroplasty ${ }^{19}$ and primary total knee arthroplasty. ${ }^{20}$

The prevalence of frailty varies as a function of the method used to measure frailty, the study population, and the threshold used to classify an individual as frail. Our findings demonstrate that frailty is present in approximately $15.5 \%$ of the elective posterior thoracolumbar 
Table 2 Multivariate Logistic Regression to Determine the Effect of $\mathrm{mFI}$ on Post-Operative Outcomes

\begin{tabular}{|c|c|c|c|c|}
\hline \multirow{3}{*}{$\begin{array}{l}\text { Effect } \\
\text { Any complication }\end{array}$} & \multicolumn{4}{|l|}{ LSF } \\
\hline & \multirow{3}{*}{$\begin{array}{l}\text { OR } \\
0.964\end{array}$} & \multicolumn{2}{|c|}{$\begin{array}{l}\text { 95\% Confidence } \\
\text { Limits }\end{array}$} & \multirow[t]{2}{*}{ p value } \\
\hline & & & & \\
\hline Age & & 0.893 & 1.042 & 0.354 \\
\hline Gender & 1.198 & 0.436 & 3.294 & 0.726 \\
\hline BMI & 1.777 & 0.981 & 3.218 & 0.058 \\
\hline ASA & 1.612 & 0.735 & 3.537 & 0.233 \\
\hline $\mathrm{mFI}$ & 12.384 & 4.284 & 35.798 & $<0.001 *$ \\
\hline Surgical level & 1.205 & 0.947 & 1.534 & 0.129 \\
\hline \multicolumn{5}{|l|}{ Major complication } \\
\hline Age & 1.025 & 0.948 & 1.109 & 0.536 \\
\hline Gender & 1.997 & 0.699 & 5.711 & 0.197 \\
\hline BMI & 2.624 & 1.464 & 4.705 & $0.00 I^{*}$ \\
\hline ASA & 1.324 & 0.584 & 3.004 & 0.502 \\
\hline $\mathrm{mFI}$ & 5.680 & 2.078 & 15.525 & $0.001 *$ \\
\hline Surgical level & 1.117 & 0.852 & 1.463 & 0.423 \\
\hline \multicolumn{5}{|l|}{ Minor complication } \\
\hline Age & 0.889 & 0.810 & 0.974 & $0.012 *$ \\
\hline Gender & 0.733 & 0.241 & 2.230 & 0.584 \\
\hline BMI & 0.805 & 0.420 & $\mathrm{I} .544$ & 0.514 \\
\hline ASA & 2.358 & 0.942 & 5.903 & 0.067 \\
\hline $\mathrm{mFI}$ & 6.430 & 2.133 & 19.389 & $0.001 *$ \\
\hline Surgical level & 1.267 & 0.989 & 1.624 & 0.062 \\
\hline \multicolumn{5}{|l|}{ Adverse discharge } \\
\hline Age & 0.983 & 0.898 & 1.076 & 0.710 \\
\hline Gender & 1.436 & 0.456 & 4.527 & 0.536 \\
\hline BMI & 1.529 & 0.814 & 2.875 & 0.187 \\
\hline ASA & 0.988 & 0.389 & 2.504 & 0.979 \\
\hline $\mathrm{mFI}$ & 3.442 & 1.119 & 10.588 & $0.031 *$ \\
\hline Surgical level & 1.274 & 0.980 & 1.657 & 0.071 \\
\hline \multirow[t]{2}{*}{ Effect } & \multicolumn{4}{|l|}{ SSF } \\
\hline & OR & \multicolumn{2}{|c|}{ 95\% Confidence limits } & p value \\
\hline \multicolumn{5}{|l|}{ Any complication } \\
\hline Age & 1.058 & 0.999 & 1.121 & 0.053 \\
\hline Gender & 0.898 & 0.426 & 1.893 & 0.777 \\
\hline BMI & 0.953 & $0.55 \mathrm{I}$ & 1.647 & 0.862 \\
\hline ASA & 1.380 & 0.796 & 2.393 & 0.251 \\
\hline $\mathrm{mFI}$ & 3.901 & 1.792 & 8.489 & $0.001 *$ \\
\hline Surgical level & 1.284 & 0.591 & 2.789 & 0.528 \\
\hline \multicolumn{5}{|l|}{ Major complication } \\
\hline Age & 1.016 & 0.936 & 1.103 & 0.705 \\
\hline Gender & 2.055 & 0.749 & 5.638 & 0.162 \\
\hline BMI & 0.848 & 0.346 & 2.076 & 0.718 \\
\hline ASA & 1.357 & 0.614 & 2.999 & 0.450 \\
\hline $\mathrm{mFI}$ & 2.284 & 0.799 & 6.533 & 0.123 \\
\hline Surgical level & 1.218 & 0.401 & 3.702 & 0.728 \\
\hline
\end{tabular}

(Continued)
Table 2 (Continued).

\begin{tabular}{|l|l|l|l|l|}
\hline \multirow{2}{*}{ Effect } & \multicolumn{3}{l}{ LSF } & p value \\
\cline { 2 - 5 } & OR & \multicolumn{2}{l|}{$95 \%$ Confidence } \\
Limits & \\
\hline Minor complication & & & & \\
Age & 1.067 & 1.003 & 1.135 & $0.04 I^{*}$ \\
Gender & 0.684 & 0.298 & 1.571 & 0.371 \\
BMI & 1.026 & 0.578 & 1.819 & 0.930 \\
ASA & 1.597 & 0.881 & 2.896 & 0.123 \\
mFI & 2.381 & 1.066 & 5.319 & $0.034^{*}$ \\
Surgical level & 1.310 & 0.560 & 3.065 & 0.534 \\
\hline Adverse discharge & & & & \\
Age & 0.975 & 0.876 & 1.086 & 0.647 \\
Gender & 0.267 & 0.049 & 1.472 & 0.129 \\
BMI & 0.823 & 0.269 & 2.512 & 0.732 \\
ASA & 3.643 & 1.240 & 10.702 & $0.019 *$ \\
mFI & 3.501 & 0.930 & 13.180 & 0.064 \\
Surgical level & 1.206 & 0.277 & 5.250 & 0.802 \\
\hline
\end{tabular}

Note: $* \mathrm{P}<0.05$

Abbreviations: LSF, long spinal fusion; ASA, American Society of Anesthesiologists; BMI, body mass index; SSF, short spinal fusion; mFI, Modified Frailty Index; OR, odds ratio.

fusion surgery population, with a frailty threshold $\geq 0.21$ (21.9\% in the LSF group and $11.8 \%$ in the SSF group). The incidence of frailty in our study was higher than the study which showed that a total of 2041 patients (4\%) were frail with an 11 -item $\mathrm{mFI} \geq 0.21$, and the prevalence increasing to $8 \%$ in patients $>65$ years of age. ${ }^{9}$ In another study, the author used the ASD-FI to calculate frailty scores for 266 ASD patients; $51 \%$ were categorized as not frail, $34 \%$ as frail, $15 \%$ as severely frail, and the overall mean ASD-FI score was $0.29 .{ }^{40}$ Passias et $\mathrm{al}^{35}$ developed a simplified frailty index for cervical deformity patients; the mean CD-FI was $0.31 \pm 0.14$. The breakdown of patients based on the CD-FI category was as follows: not frail, $47.9 \%$; frail, $46.3 \%$; and severely frail, $5.8 \%$.

A useful cut-off value regarding several complications and mortality should be defined. We elected to use 0.21 as the cut-off point for frailty. Prior studies involving different surgeries have used a cut-off point of $0.27 .^{23,41} \mathrm{In}$ actuality, the results would have been the same whether or not we used 0.21 or 0.27 as the cut-off point because we categorized patients as not frail $(\mathrm{mFI}=0)$, pre-frail $(\mathrm{mFI}$ $<0.21$ ), or frail ( $\mathrm{mFI} \geq 0.21)$. In the present study only one patient in the SSF group died within 30 days after spinal surgery, so we could not perform a statistical analysis. Other studies have reported that increased mFI scores are independent predictors of 30-day mortality in the general 

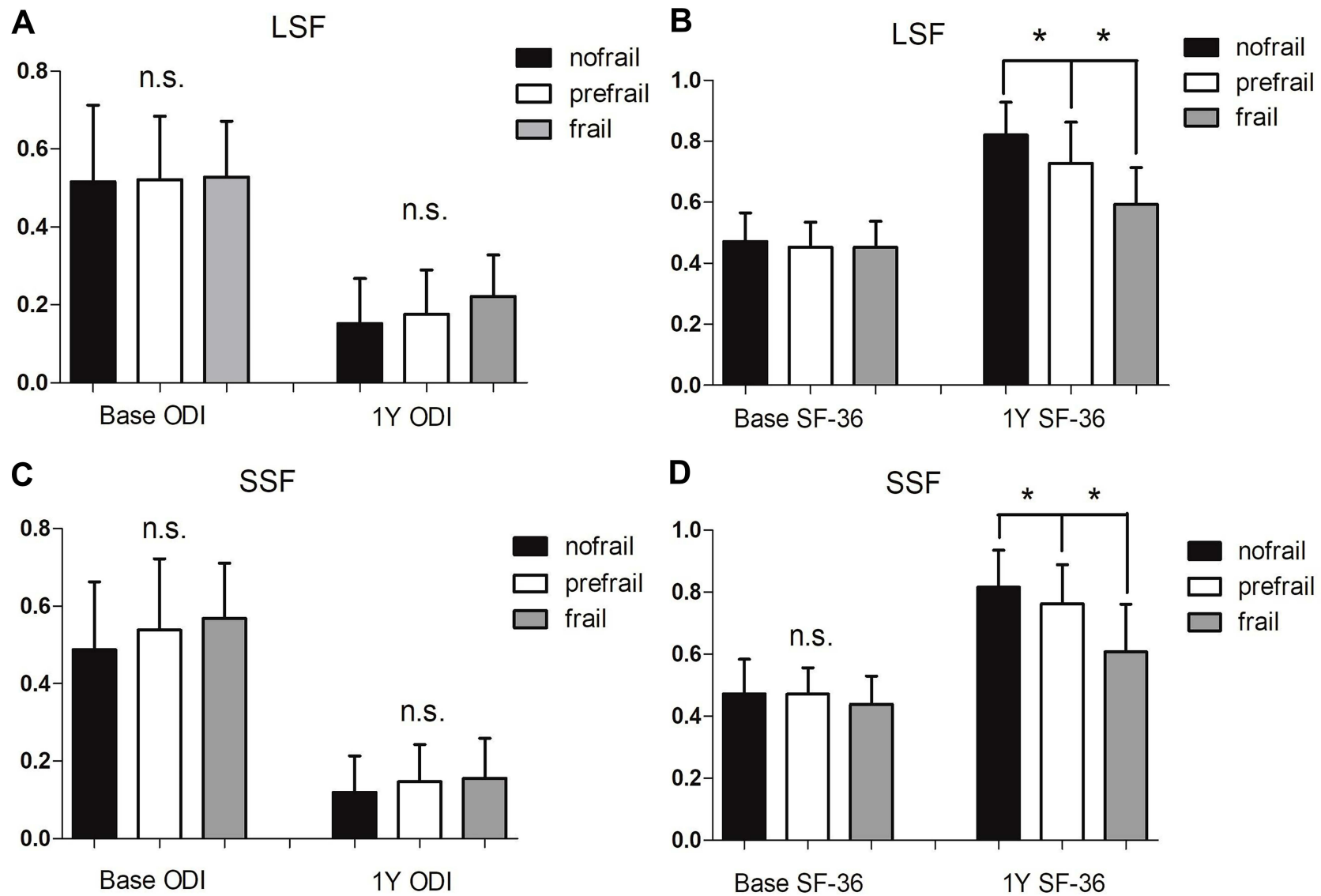

Figure 4 Modified Frailty Index $(\mathrm{mFI})$ score and clinical outcomes in surgically treated DSD subjects. (A) Oswestry Disability Index and (B) SF-36 scores at baseline and at the I-year follow-up evaluation viewed by degrees of frailty (not frail, pre-frail, or frail) based on $\mathrm{mFI}$ in the long spinal fusion group. (C) Oswestry Disability Index and (D) SF-36 scores at baseline and at the I-year follow-up evaluation, viewed by degrees of frailty (not frail, pre-frail, or frail) based on $\mathrm{mFI}$ in the short spinal fusion group. $* \mathrm{P}<0.05$.

spine surgery population, ${ }^{41}$ as well as patients undergoing anterior cervical discectomy and fusion $(\mathrm{ACDF}),{ }^{10}$ posterior cervical fusion, ${ }^{10} \mathrm{ASD},{ }^{23}$ and degenerative spine condition procedures. ${ }^{9}$ Nevertheless, one study reported that increased $\mathrm{mFI}$ scores did not correlate with increased 30 day mortality rates for patients undergoing anterior lumbar interbody fusion (ALIF). ${ }^{22}$

We found that increasing $\mathrm{mFI}$ scores correlated with higher rates of complications. This correlation has also been reported in patients undergoing general spine surgical, ${ }^{41} \mathrm{ACDF},{ }^{10}$ PCF, ${ }^{10}$ ALIF, $^{22}$ and ASD procedure. ${ }^{23}$ In one study, a mFI $\geq 0.36$ was reported to be an independent predictor of ClavienDindo IV complications, ${ }^{10}$ however, Adams et $\mathrm{al}^{15}$ found that a mFI score $>0.45$ was an independent predictor of mortality and Clavien-Dindo IV complications. In contrast to other surgical groups, Charest-Morin et $\mathrm{al}^{25}$ concluded that based on a relatively low sample size together with a low prevalence of frailty $(20 \%)$ that frailty $(\mathrm{mFI})$ did not predict acute care complications in a select population of elderly patients undergoing simple lumbar spine surgery for DSD. In our study even though we demonstrated that frailty was an independent predictor of post-operative outcomes, the predictive ability was different in the LSF and SSF groups. Based on multivariable regression analysis, a significant association existed between higher mFI scores with any complication, major complications, and minor complications in the LSF group, but with any complication and minor complications in the SSF group. Of note, LSF requires more invasive surgery, while SSF requires less invasive surgery; the less invasive the surgery, the less likely frailty and co-morbidities lead to surgical complications and poor clinical outcomes. Therefore, mFI should be widely used in more invasive surgery to predict post-operative complications.

In the spine literature, data on the correlation between $\mathrm{mFI}$ with prolonged LOS and an elevated risk of institutional discharge are inconsistent. A prolonged LOS and discharge to a new facility are both predicted by the $\mathrm{mFI}$ based on unadjusted and adjusted analyses. ${ }^{9}$ Similarly, the mean hospital stay is 2.1 times longer for severely frail patients compared with patients who are not frail; ${ }^{40}$ 
however, it has been reported that high frailty scores are not associated with a $\operatorname{LOS}>5$ days. $^{22}$ In addition, others have found that the discharge disposition and LOS did not correlate significantly with frailty. ${ }^{34}$ In our study the rate of adverse discharges and LOS increased from $6.67 \%$ (16.93 days) to $50 \%$ (29 days) between $\mathrm{mFI}$ scores of 0 and $\geq 0.36$ in the LSF group. A similar trend with respect to the rate of adverse discharges and LOS was also observed in the SSF group.

There are few previous reports describing the impact of frailty on clinical outcomes in older patients with DSD. In the present study comparisons of post-operative clinical outcomes showed that both the ODI and SF-36 scores deteriorated in the LSF and SSF groups along with an increase in the $\mathrm{mFI}$. Yagi et $\mathrm{al}^{24}$ found that postsurgical clinical outcomes improved for degenerative spondylolisthesis and lumbar spinal canal stenosis, but declined significantly for adults with spinal deformities as the $\mathrm{mFI}$ deteriorated. Yagi et $\mathrm{al}^{24}$ explained the reasons as follows: the surgery for ASD is more invasive than that for DS or LSCS; and the factors that influence clinical outcomes vary among adult spinal disorders. In our study, however, both the ODI and SF-36 scores improved after surgery compared with the pre-operative scores in the two groups, even though the surgery for LSF was more invasive than that for SSF. Because the follow-up time was short, further study about mFI and quality of life in patients is needed.

There were some limitations in the present study. First, this is a retrospective analysis of prospectively collected data. Therefore, the risk of selection bias influencing the results cannot be excluded. Second, we divided the patients into LSF and SSF groups; however, the pathophysiology between different DSDs (LDH, DS, LSCS, and ASD) may influence the severity of frailty, then confuse the results. Third, important variables, such as degree of neurologic involvement, nutritional status, and degree of osteoporosis are important covariates to consider, but were not captured in our study. Thus, future studies should specifically explore the effect of these variables. Another potential limitation was that patients in the study included those who sought treatment for the co-morbidities and those who did not, and the status of each co-morbidity could significantly affect the development of post-operative events. Subjects who received treatment for any co-morbidities may yield results more similar to those without co-morbidities, achieving better results than those who did not seek treatment for comorbidities. Lastly, radiographic findings were not included in our study, which were important considerations in previous spinal studies.

\section{Conclusions}

Despite these limitations, this study demonstrated that $\mathrm{mFI}$ is a useful assessment tool that can be incorporated into the pre-operative evaluation for patients undergoing surgery for DSD, especially for patients who undergo a LSF. The any complication rate for the patients we studied with an mFI score $>0.21$ or 0.27 was $20.9 \%$. Because the older population is increasing along with the rate of surgery for DSD, the impact of mFI on risk stratification and postoperative outcomes is increasingly important. Additional prospective studies are needed to further validate the role of frailty in this population. An mFI exclusive to spinal surgery will be needed to improve outcomes.

\section{Funding}

No external funding was used for this study.

\section{Disclosure}

The authors report no conflicts of interest.

\section{References}

1. UNPD (United Nations Population Division). World population prospects: The 2015 Revision. New York: Department of Economic and Social Affairs; 2015a.

2. Deiner S, Westlake B, Dutton RP. Patterns of surgical care and complications in elderly adults. $J$ Am Geriatr Soc. 2014;62:829-835. doi:10.1111/jgs. 12794

3. Vonlanthen R, Slankamenac K, Breitenstein S, Puhan MA, Clavien PA. The impact of complications on costs of major surgical procedures a cost analysis of 1200 patients. Ann Surg. 2011;254:907-913. doi:10.1097/SLA.0b013e31821d4a43

4. Lees M, Merani S, Tauh K, Khadaroo RG. Perioperative factors predicting poor outcome in elderly patients following emergency general surgery: a multivariate regression analysis. Can J Surg. 2015;58 (5):312-317. doi:10.1503/cjs.011614

5. Lawrence VA, Hazuda HP, Cornell JE, et al. Functional independence after major abdominal surgery in the elderly. $J$ Am Coll Surg. 2004;199:762-772. doi:10.1016/j.jamcollsurg.2004.05.280

6. Capua JD, Somani S, Kim JS, Phan K, Cho SK. Analysis of risk factors for major complications following elective posterior lumbar fusion. Spine. 2017;42:1347-1354. doi:10.1097/BRS.0000000000002 090

7. Lee NJ, Guzman JZ, Kim J, Skovrlj B, Cho SK. A comparative analysis among the SRS M\&M, NIS, and KID databases for the adolescent idiopathic scoliosis. Spine Deform. 2016;4(6):420-424. doi:10.1016/j.jspd.2016.05.005

8. Mak PHK, Campbell RCH, Irwin MG. The ASA physical status classification: inter-observer consistency. Anaesth Intensive Care. 2002;30(5):633-640. doi:10.1177/0310057X0203000516

9. Flexman AM, Charest-Morin R, Stobart L, Street J, Ryerson CJ. Frailty and postoperative outcomes in patients undergoing surgery for degenerative spine disease. Spine J. 2016;16:1315-1323. doi:10.1016/j.spinee.2016.06.017 
10. Shin JI, Kothari P, Phan K, Kim JS, Leven D. Frailty index as a predictor of adverse postoperative outcomes in patients undergoing cervical spinal fusion. Spine. 2017;42(5):304-310. doi:10.1097/ BRS.0000000000001755

11. Iqbal J, Denvir M, Gunn J. Frailty assessment in elderly people. Lancet. 2013;381:1985-1986.

12. Partridge JSL, Harari D, Dhesi JK. Frailty in the older surgical patient: a review. Age Ageing. 2012;41:142-147. doi:10.1093/ageing/afr 182

13. Bhagat S, Vozar V, Lutchman L, Crawford RJ, Rai AS. Morbidity and mortality in adult spinal deformity surgery: norwich spinal unit experience. Eur Spine J. 2013;22:42-46. doi:10.1007/s00586-012-2627-y

14. Velanovich V, Antoine H, Swartz A, Peters D, Rubinfeld I. Accumulating deficits model of frailty and postoperative mortality and morbidity: its application to a national database. J Surg Res. 2013;183:104-110. doi:10.1016/j.jss.2013.01.021

15. Adams P, Ghanem T, Stachler R, Hall F, Velanovich V, Rubinfeld I. Frailty as a predictor of morbidity and mortality in inpatient head and neck surgery. JAMA Otolaryngol Head Neck Surg. 2013;13 9:783-789. doi:10.1001/jamaoto.2013.3969

16. Arya S, Kim SI, Duwayri Y, et al. Frailty increases the risk of 30-day mortality, morbidity, and failure to rescue after elective abdominal aortic aneurysm repair independent of age and comorbidities. J Vasc Surg. 2015;61:324-331. doi:10.1016/j.jvs.2014.08.115

17. Tsiouris A, Hammoud ZT, Velanovich V, Hodari A, Borgi J, Rubinfeld I. A modified frailty index to assess morbidity and mortality after lobectomy. J Surg Res. 2013;183(1):40-46. doi:10.1016/j. jss.2012.11.059

18. Lascano D, Pak JS, Kates M, et al. Validation of a frailty index in patients undergoing curative surgery for urologic malignancy and comparison with other risk stratification tools. Urol Oncol. 2015;33 (10):421-426. doi:10.1016/j.urolonc.2015.06.002

19. Bellamy JL, Runner RP, Vu CPCL, Schenker ML, Roberson JR. Modified frailty index is an effective risk assessment tool in primary total hip arthroplasty. $J$ Arthroplasty. 2017;32:2963-2968. doi:10.1016/j.arth.2017.04.056

20. Runner RP, Bellamy JL, Vu CCL, Erens GA, Schenker ML, Guild GN. Modified frailty index is an effective risk assessment tool in primary total knee arthroplasty. J Arthroplasty. 2017;32: S177-S182. doi:10.1016/j.arth.2017.03.046

21. Kessler RA, Ramos RDLG, Purvis TE, et al. Impact of frailty on complications in patients with thoracic and thoracolumbar spinal fracture. Clin Neurol Neurosurg. 2018;169:161-165. doi:10.1016/j. clineuro.2018.04.014

22. Phan K, Kim JS, Lee NJ, et al. Frailty is associated with morbidity in adults undergoing elective anterior lumbar interbody fusion (ALIF) surgery. Spine J. 2017;17:538-544. doi:10.1016/j.spinee.2016.10.023

23. Leven DM, Lee NJ, Kothari P, et al. Frailty index is a significant predictor of complications and mortality after surgery for adult spinal deformity. Spine. 2016;41(23):E1394-E1401. doi:10.1097/BRS.000 0000000001886

24. Yagi M, Fujita N, Okada E, et al. Impact of frailty and comorbidities on surgical outcomes and complications in adult spinal disorders. Spine. 2018;43:1259-1267. doi:10.1097/BRS.0000000000002596

25. Charest-Morin RL, Street J, Zhang H, et al. Frailty and sarcopenia do not predict adverse events in an elderly population undergoing non-complex primary elective surgery for degenerative conditions of the lumbar spine. Spine J. 2018;18:245-254. doi:10.1016/j. spinee.2017.07.003
26. Yagi M, Michikawa T, Hosogane N, et al. Treatment for frailty does not improve complication rates in corrective surgery for adult spinal deformity. Spine. 2019;44:723-731. doi:10.1097/BRS.000000000000 2929

27. Saxton A, Velanovich V. Preoperative frailty and quality of life as predictors of postoperative complications. Ann Surg. 2011;253 (6):1223-1229. doi:10.1097/SLA.0b013e318214bce7

28. Searle SD, Mitnitski A, Gahbauer EA, Gill TM, Rockwood K. A standard procedure for creating a frailty index. BMC Geriatr. 2008;8:24. doi:10.1186/1471-2318-8-24

29. Rockwood K, Song X, Mitnitski A. Changes in relative fitness and frailty across the adult lifespan: evidence from the Canadian National population health survey. Can Med Assoc J. 2011;183:E487-E494. doi:10.1503/cmaj.101271

30. Carreon LY, Puno RM, Dimar I JR, Glassman SD, Johnson JR Perioperative complications of posterior lumbar decompression and arthrodesis in older adults. J Bone Joint Surg Am. 2003;85 (11):2089-2092. doi:10.2106/00004623-200311000-00004

31. Fried LP, Tangen CM, Walston J, et al. Frailty in older adults: evidence for a phenotype. J Gerontol a Biol Sci Med Sci. 2001;56: M146-156. doi:10.1093/gerona/56.3.M146

32. Miller EK, Neuman BJ, Jain A, et al. An assessment of frailty as a tool for risk stratification in adult spinal deformity surgery. Neurosurg Focus. 2017;43:E3. doi:10.3171/2017.10.FOCUS17472

33. Reid DBC, Daniels AH, Ailon T, et al. Frailty and health-related quality of life improvement following adult spinal deformity surgery. World Neurosurg. 2018;112:e548-e554. doi:10.1016/j.wneu.2018.01. 079

34. Miller EK, Ailon T, Neuman BJ, et al. Assessment of a novel adult cervical deformity frailty index as a component of preoperative risk stratification. World Neurosurg. 2018;109:e800-e806. doi:10.1016/j. wneu.2017.10.092

35. Passias PG, Bortz CA, Segreto FA, et al. Development of a modified cervical deformity frailty index: a streamlined clinical tool for preoperative risk stratification. Spine. 2019;44:169-176. doi:10.1097/ BRS.0000000000002778

36. de Vries NM, Staal JB, van Ravensberg CD, Hobbelen JS, Olde Rikkert MG, Nijhuis-van der Sanden MW. Outcome instruments to measure frailty: a systematic review. Ageing Res Rev. 2011;10:104-114. doi:10.1016/j.arr.2010.09.001

37. Song X, Mitnitski A, Rockwood K. Prevalence and 10-year outcomes of frailty in older adults in relation to deficit accumulation. $\mathrm{J} \mathrm{Am}$ Geriatr Soc. 2010;58:681-687. doi:10.1111/j.1532-5415.2010.02764.x

38. Moskven E, Bourassa-Moreau É, Charest-Morin R, Flexman A, Street J. The impact of frailty and sarcopenia on postoperative outcomes in adult spine surgery. A systematic review of the literature. Spine. 2018;18:2354-2369. doi:10.1016/j.spinee.2018.07.008

39. Rockwood K, Andrew M, Mitnitski A. A comparison of two approaches to measuring frailty in elderly people. J Gerontol a Biol Sci Med Sci. 2007;62:738-743. doi:10.1093/gerona/62.7.738

40. Miller EK, Vila-Casademunt A, Neuman BJ, et al. External validation of the adult spinal deformity (ASD) frailty index (ASD-FI). Eur Spine J. 2018;27:2331-2338. doi:10.1007/s00586-018-5575-3

41. Ali R, Schwalb JM, Nerenz DR, Antoine HJ, Rubinfeld I. Use of the modified frailty index to predict 30-day morbidity and mortality from spine surgery. J Neurosurg Spine. 2016;25:537-541. doi:10.3171/ 2015.10.SPINE14582 


\section{Publish your work in this journal}

Clinical Interventions in Aging is an international, peer-reviewed journal focusing on evidence-based reports on the value or lack thereof of treatments intended to prevent or delay the onset of maladaptive correlates of aging in human beings. This journal is indexed on PubMed Central, MedLine, CAS, Scopus and the Elsevier
Bibliographic databases. The manuscript management system is completely online and includes a very quick and fair peer-review system, which is all easy to use. Visit http://www.dovepress.com/ testimonials.php to read real quotes from published authors. 